\title{
Moyamoya: A Review of the Disease and Current Treatments
}

\author{
Eliza Anderson \\ Third Year Medical Student, Jefferson Medical College \\ Cory D. Bovenzi \\ Jefferson University \\ Thana Theofanis, MD \\ Department of Neurological Surgery, Thomas Jefferson University Hospital \\ Nohra Chalouhi, MD \\ Department of Neurological Surgery, Thomas Jefferson University Hospital \\ Robert H. Rosenwasser MD \\ Department of Neurological Surgery, Thomas Jefferson University Hospital
}

Third Year Medical Student, Thomas Jefferson University Hospital, Jefferson Medical College, Thomas

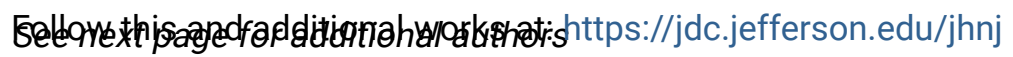 Let us know how access to this document benefits you}

\section{Recommended Citation}

Anderson, Eliza; Bovenzi, Cory D.; Theofanis, MD, Thana; Chalouhi, MD, Nohra; Rosenwasser MD, Robert H.; Jabbour, MD, Pascal; and Tjoumakaris, MD, Stavropoula (2014) "Moyamoya: A Review of the Disease and Current Treatments," JHN Journal: Vol. 9 : Iss. 2 , Article 1.

DOI: https://doi.org/10.29046/JHNJ.009.2.001

Available at: https://jdc.jefferson.edu/jhnj/vol9/iss2/1

This Article is brought to you for free and open access by the Jefferson Digital Commons. The Jefferson Digital Commons is a service of Thomas Jefferson University's Center for Teaching and Learning (CTL). The Commons is a showcase for Jefferson books and journals, peer-reviewed scholarly publications, unique historical collections from the University archives, and teaching tools. The Jefferson Digital Commons allows researchers and interested readers anywhere in the world to learn about and keep up to date with Jefferson scholarship. This article has been accepted for inclusion in JHN Journal by an authorized administrator of the Jefferson Digital Commons. For more information, please contact: JeffersonDigitalCommons@jefferson.edu. 


\section{Moyamoya: A Review of the Disease and Current Treatments}

\section{Authors}

Eliza Anderson; Cory D. Bovenzi; Thana Theofanis, MD; Nohra Chalouhi, MD; Robert H. Rosenwasser MD; Pascal Jabbour, MD; and Stavropoula Tjoumakaris, MD 


\section{Moyamoya: A Review of the Disease and Current Treatments}

\author{
Eliza Anderson, $\mathrm{BA}^{1}$; Cory Bovenzi, $\mathrm{BA}^{1}$; Thana Theofanis, $\mathrm{MD}^{2}$; \\ Nohra Chalouhi, MD²; Robert H. Rosenwasser, MD²; Pascal Jabbour, MD²; \\ Stavropoula Tjoumakaris, MD $^{2}$ \\ 1 Third Year Medical Student, Jefferson Medical College, Philadelphia, PA \\ 2 Department of Neurological Surgery, Thomas Jefferson University Hospital, Philadelphia, PA
}

\section{INTRODUCTION}

Moyamoya disease is a rare progressive cerebrovascular disease characterized by bilateral stenosis of vasculature of the Circle of Willis, specifically the distal internal carotid arteries, that leads to extensive collateral circulation. These dilated collateral vessels are described as having a hazy "puff of smoke" appearance on angiography. "Moyamoya" is the Japanese word for this characteristic appearance. The disease was originally described in Japan in $1957^{1}$ and introduced to the English literature in $1969 .^{2}$ The disease is most known for its distribution in Asian populations, but recently there has been more research and attention given to moyamoya in Europe and North American Moyamoya disease presents clinically due to the ischemic and hemorrhagic complications of abnormal cerebral vascularity. 3,4

\section{Epidemiology}

Moyamoya disease was originally described in Japanese populations but is present in a variety of ethnicities. ${ }^{3,5,6}$ In Japan, the incidence per 100,000 patient years is between 0.35 to 0.943 with a male: female ratio of $1: 1.87$. In the US, incidence ranged from 0.05 to 0.17 per 100,000 patient years with a similar gender distribution. 3,6 Other population studies have not been as robust but European studies show moyamoya statistics that are more similar to American findings than those of Asian moyamoya findings. ${ }^{4}$ There is a bimodal distribution of incidence: in early childhood and adulthood, but the doublepeaked incidence is less dramatic in the US and Europe. ${ }^{4,8}$ Children typically present with the ischemic symptoms and adults can present with either ischemic or hemorrhagic type, with the ischemic type predominating. ${ }^{5,9}$ Overall, the hemorrhagic type is more common in Asia than the U.S. ${ }^{9}$ The incidence has been increasing with time, which may be due to increased awareness. ${ }^{5}$

\section{Etiology}

The etiology of moyamoya disease is largely unknown. However, there are genetic susceptibilities and biochemical correlates that warrant further research. This importance is highlighted in the $10-15 \%$ of moyamoya disease cases that are familial. ${ }^{10}$ The proposed mechanism of inheritance is autosomal dominant with incomplete penetrance but it is likely there are polygenic interactions as well. ${ }^{11}$ Currently, screening is not recommended for moyamoya disease.

The first gene associated with moyamoya disease was RNF213 on chromosome $17 .^{12}$ Animal models show that knockout of this gene causes arterial abnormalities with wall malformation and abnormal angiogenesis. ${ }^{13}$ Another study showed that different mutations of this ring finger protein are associated with different clinical presentations of moyamoya: R4810K mutation with the ischemic form and A4399T mutation with the hemorrhagic form. ${ }^{14}$

There is evidence of a dysregulation of a variety of extracellular matrix proteins in moyamoya, including basic fibroblast growth factor, ${ }^{15}$ transforming growth factor beta116 , and vascular endothelial growth factor. ${ }^{17} \mathrm{~A}$ tentative pathologic process is believed to be mediated by intimal thickening and media attenuation in proximal vessels, along with abnormal smooth muscle cell turnover and neovascularization in distal vessels. ${ }^{18}$

\begin{abstract}
Moyamoya Syndrome
Moyamoya disease is characterized by an idiopathic abnormal vasculature adjacent to the circle of Willis with extensive compensatory collateral vessels. Moyamoya syndrome is a separate entity, associated with another disease that causes a similar angiographic appearance. ${ }^{19}$ The most common examples of diseases that can cause moyamoya syndrome are sickle-cell disease, neurofibromatosis type I, cranial irradiation, and Down syndrome. Even without these risk factors, a unilateral presentation is also considered to be moyamoya syndrome since moyamoya disease is defined as a bilateral disease. ${ }^{20}$ The distinction between these two entities is critical for an appropriate clinical approach.
\end{abstract}

\section{CLINICAL PRESENTATION}

Moyamoya disease can be asymptomatic in early stages, or present with a range of symptoms associated with the abnormal vasculature including headaches, seizures, hemiparesis, and sensory impairment. The two major types of manifestations are ischemic and hemorrhagic. Ischemic symptoms are associated with insufficient perfusion and infarcts are typically small and located in the basal ganglia. ${ }^{21}$ Hemorrhages can occur due to the poorly formed collateral arterial supply and result in a worse prognosis. ${ }^{5}$ Roughly half of patients have a single symptomatic episode and half have multiple recurrences of ischemic events. ${ }^{23}$ Recurrences in the pediatric population are associated with stress, hyperventilation, dehydration, and crying, which are important factors to recognize and explain to the patient's family for prevention measures. ${ }^{19}$ 


\section{DIAGNOSIS AND IMAGING}

It is important that Moyamoya is considered in patients with stroke-like symptoms due to its unique clinical approach. This is especially important to keep in mind with pediatric patients since $6 \%$ of pediatric strokes are due to moyamoya disease. 5,9,22

Due to the symptoms at presentation, the initial imaging study of these patients is typically computed tomography (CT). CT can identify ischemic lesions from the basal ganglia (earlier stages) to the cortex (later stages) but can be normal if the lesions are small. ${ }^{24}$ Commonly, the diagnosis of moyamoya disease requires multiple imaging modalities. Brain MRI is more sensitive for these smaller lesions and can also identify punctuate flow voids in the basal ganglia which is highly suggestive of moyamoya disease. ${ }^{19}$

The gold standard for diagnosis is conventional cerebral angiography. Transcranial Doppler studies can also be useful to noninvasively detect stenotic vessels via an increased flow rate and track changes in this flow over time. ${ }^{25}$

\section{THERAPEUTIC OPTIONS}

The mainstay of treatment for patients of all age groups presenting with Moyamoya continues to be neurosurgical intervention. Surgery is the only means by which the morbidity and mortality of the disease can be dramatically reduced. There is no agreed upon medical regimen, and the only medical options available treat the complications of the disease. For example; aspirin may be given to inhibit the formation of microthromboemboli that could cause ischemia (surgical patients are given this routinely); calcium channel blockers have been reported to improve intractable headaches; and fluids are given to avoid hypoperfusion. ${ }^{26}$

The disease is inevitably progressive, ${ }^{27}$ and the single most important prognostic indicator is neurologic status at the time of treatment. ${ }^{26}$ Surgery is considered first line as a preventative measure against stroke and neurologic decline, ${ }^{27}$ serious complications for the relatively young patient population affected by moyamoya. If there are contraindications to surgery, such as a recent stroke or infection, or if the patient has adequate collateral circulation, medical management may be chosen over surgery. ${ }^{27,28}$ Symptomatic patients treated medically show much higher rates of recurrent stroke than surgical patients. ${ }^{29}$

\section{Revascularization}

Surgical revascularization techniques aim to increase cerebral blood flow to affected territories, and to indirectly shrink the aberrant collaterals that have formed as a result of ICA stenosis. A variety of direct, indirect and combined surgical techniques have been employed, which can decrease the frequency of ischemic and hemorrhagic events that occur and therefore improve functional outcomes. ${ }^{30}$ For the purpose of discussion, direct and indirect approaches can be separated into two distinct categories. In practice, however, the combined approach more effectively promotes long-term revascularization, and has not been proven to increase complication rates over one technique alone. ${ }^{23,27}$

\section{Direct Bypass}

Direct revascularization involves the anastomosis of the superficial temporal artery with the middle cerebral artery, distal to the stenotic region. ${ }^{30}$ This allows for an immediate increase in blood flow to previously hypoperfused territories of the brain. This method has better revascularization outcomes than indirect methods alone. ${ }^{23}$ One concerning complication of this method, however, if there is inadequate blood pressure control, is postoperative hyperperfusion, which can lead to seizures. ${ }^{27}$ Also, this bypass is not always feasible in children as their vessels are of a smaller diameter, ${ }^{27}$ so indirect methods are often relied upon in the pediatric population. ${ }^{31}$

\section{Indirect Revascularization}

Indirect revascularization describes a number of surgeries with the unifying theme of applying richly vascular tissue on top of the hypoperfused region in order to promote angiogenesis. ${ }^{27}$ Ultimately, the transposed vessel anastomoses with the existing vasculature, which can significantly improve flow through the previously undersupplied vessels. Potential issues with this technique include the time delay of weeks to months after surgery before the target tissue is perfused, and the potential for mass effect, as you are introducing relatively large sections of tissue into critically eloquent areas of cerebral cortex. ${ }^{32}$ Tissue can be taken from, for example, the omentum (omental transplantation) or the temporalis muscle (encephalomyosynangiosis), but the three most commonly utilized indirect techniques in North America are encephaloduroarteriosynangiosis (EDAS), encephaloduroarteriomyosynangiosis (EDAMS), and multiple burr hole placement $(\mathrm{MBH}){ }^{30}$

The EDAS procedure requires suturing the STA and a tissue cuff to the dura overlying the target area. Burr holes are used to facilitate the craniotomy. Many variations exist, but one popular technique, pial synangiosis, involves attaching the STA and tissue cuff directly to the pia. EDAMS is a more involved procedure that involves utilization of the deep temporal, superficial temporal, and middle meningeal arteries. ${ }^{32} \mathrm{MBH}$ is the least invasive technique, more commonly used in children than adults, and requires the placement of a number of burr holes through small cuts in the periosteum. This allows for targeting of specific tissue regions and promotes angiogenesis in those areas. ${ }^{32}$

\section{PROGNOSIS}

Moyamoya, as mentioned above, is inherently progressive. ${ }^{25,26}$ The natural history of the disease cannot be changed by intervention, but it can be delayed significantly, and the functional status of the patient kept remarkably intact. ${ }^{30}$ Outcomes are best predicted by neurologic status at treatment, and presentation with a stroke (hemorrhagic more than ischemic) was found to be the greatest predictor of mortality during hospital stay for treatment. 5,26,27 In North America, where presentation is primarily ischemic regardless of age group, childhood diagnosis is considered to have a worse prognosis. ${ }^{30}$ When left untreated, even asymptomatic patients will progress to the point of potentially devastating recurrent strokes, but with early diagnosis and surgical intervention individuals can live for many years with a dramatically lower risk of the morbidities associated with moyamoya disease. 33,34 


\section{CONCLUSION}

Moyamoya is a predominantly Asian cerebrovascular disease of poorly understood etiology that has seen a global increase in incidence in recent decades. Moyamoya presents on angiography with bilaterally stenosed distal ICAs and hazy dilated collateral networks; this finding can be idiopathic or present with associated diseases such as sickle cell. Initial imaging is done using CT or MRI. When symptomatic, presentation of ischemic or hemorrhagic stroke is the most common. The disease is most common in young children or middle-aged adults, with a female predominance. A variety of genetic mutations have been found to associate with the disease, but none have proven to be causative; there is likely interplay between numerous genetic and environmental factors.

The disease is inevitably progressive and cannot be reversed, but prompt intervention can dramatically reduce the likelihood of stroke and neurologic decline. Treatment methods are primarily surgical, with a combined method of direct and indirect revascularization showing the best results. STA-MCA bypass carries a risk of post-operative hyperperfusion, and is not feasible in all individuals, such as in children with small diameter vessels. Indirect revascularization requires months to form the necessary anastomoses, and carries a risk of mass effect from the introduced tissue. While moyamoya is a rare disease in the US, the ability to recognize and treat affected individuals is essential, as devastating stroke can occur if it is allowed to progress.

\section{REFERENCES}

1. Oshima H, Katayama Y: Discovery of cerebrovascular moyamoya disease: Research during the late 1950s and early 1960s. Childs Nerv Syst 28:497-500, 2012

2. Suzuki J, Takaku A: Cerebrovascular "moyamoya" disease. disease showing abnormal net-like vessels in base of brain Arch Neurol 20:288-299, 1969

3. Kleinloog R, Regli L, Rinkel GJ, Klijn CJ: Regional differences in incidence and patient characteristics of moyamoya disease: A systematic review. J Neurol Neurosurg Psychiatry 83:531-536, 2012

4. Kraemer M, Heienbrok W, Berlit P: Moyamoya disease in europeans. Stroke 39:3193-3200, 2008

5. Starke RM, Crowley RW, Maltenfort M Jabbour PM, Gonzalez LF, Tjoumakaris SI, et al: Moyamoya disorder in the united states. Neurosurgery 71:93-99, 2012

6. Uchino K, Johnston SC, Becker KJ, Tirschwel $\mathrm{DL}$ : Moyamoya disease in washington state and california. Neurology 65:956-958, 2005

7. Wakai K, Tamakoshi A, Ikezaki K, Fukui M, Kawamura T, Aoki R, et al: Epidemiological features of moyamoya disease in japan: Findings from a nationwide survey. Clin Neurol Neurosurg 99 Suppl 2:S1-5, 1997

8. Baba T, Houkin K, Kuroda S: Novel epidemiological features of moyamoya disease. J Neurol Neurosurg Psychiatry 79 : 900-904, 2008

9. Han DH, Nam DH, Oh CW: Moyamoya disease in adults: Characteristics of clinical presentation and outcome after encephaloduro-arterio-synangiosis. Clin Neurol Neurosurg 99 Suppl 2:S151-5, 1997

10. Hoshino H, Izawa Y, Suzuki N, Research Committee on Moyamoya Disease: Epidemiological features of moyamoya disease in japan. Neurol Med Chir (Tokyo) 52:295-298, 2012

11. Mineharu $Y$, Takenaka $K$, Yamakawa $H$, Inoue $\mathrm{K}$, Ikeda H, Kikuta KI, et al: Inheritance pattern of familial moyamoya disease: Autosomal dominant mode and genomic imprinting. J Neurol Neurosurg Psychiatry 77:1025-1029, 2006

12. Kamada F, Aoki $Y$, Narisawa $A$, Abe $Y$, Komatsuzaki S, Kikuchi A, et al: A genomewide association study identifies RNF213 as the first moyamoya disease gene. J Hum Genet 56:34-40, 2011

13. Liu W, Morito D, Takashima S, Mineharu Y, Kobayashi H, Hitomi T, et al: Identification of RNF213 as a susceptibility gene for moyamoya disease and its possible role in vascular development. PLOS One 6:e22542, 2011

14. Wu Z, Jiang H, Zhang L, Xu X, Zhang X, Kang $Z$, et al: Molecular analysis of RNF213 gene for moyamoya disease in the chinese han population. PLoS One 7:e48179, 2012
15. Malek AM, Connors S, Robertson RL, Folkman J, Scott RM: Elevation of cerebrospinal fluid levels of basic fibroblast growth factor in moyamoya and central nervous system disorders. Pediatr Neurosurg 27:182-189, 1997

16. Liu C, Roder C, Schulte C, Kasuya H, Akagawa $H$, Nishizawa T, et al: Analysis of TGFB1 in european and japanese moyamoya disease patients. Eur J Med Genet 55:531-534, 2012

17. Sakamoto S, Kiura Y, Yamasaki F, Shibukawa M, Ohba S, Shrestha P, et al: Expression of vascular endothelial growth factor in dura mater of patients with moyamoya disease. Neurosurg Rev 31:77-81; discussion 81, 2008

18. Weinberg DG, Arnaout OM, Rahme RJ, Aoun SG, Batjer HH, Bendok BR: Moyamoya disease: A review of histopathology, biochemistry, and genetics. Neurosurg Focus 30:E20, 2011

19. Roach ES, Golomb MR, Adams R, Biller J, Daniels S, Deveber G, et al: Management of stroke in infants and children: A scientific statement from a special writing group of the american heart association stroke council and the council on cardiovascular disease in the young. Stroke 39:2644-2691, 2008

20. Research Committee on the Pathology and Treatment of Spontaneous Occlusion of the Circle of Willis, Health Labour Sciences Research Grant for Research on Measures for Infractable Diseases: Guidelines for diagnosis and treatment of moyamoya disease (spontaneous occlusion of the circle of willis). Neurol Med Chir (Tokyo) 52:245-266, 2012

21. Morgenlander JC, Goldstein LB: Recurrent transient ischemic attacks and stroke in association with an internal carotid artery web. Stroke 22:94-98, 1991

22. Hallemeier CL, Rich KM, Grubb RL,Jr, Chicoine MR, Moran CJ, Cross DT,3rd, et al: Clinical features and outcome in north american adults with moyamoya phenomenon. Stroke 37:1490-1496, 2006

23. Choi JU, Kim DS, Kim EY, Lee KC: Natural history of moyamoya disease: Comparison of activity of daily living in surgery and non surgery groups. Clin Neurol Neurosurg 99 Suppl 2:S11-8, 1997

24. Kim JM, Lee SH, Roh JK: Changing ischaemic lesion patterns in adult moyamoya disease. $J$ Neurol Neurosurg Psychiatry 80:36-40, 2009

25. Lee YS, Jung KH, Roh JK: Diagnosis of moyamoya disease with transcranial doppler sonography: Correlation study with magnetic resonance angiography. J Neuroimaging $14: 319-323,2004$

26. Scott RM, Smith ER: Moyamoya disease and moyamoya syndrome. $N$ Engl J Med 360:1226-1237, 2009

27. Smith ER, Scott RM: Moyamoya: Epidemiology, presentation, and diagnosis Neurosurg Clin N Am 21:543-551, 2010

28. Kronenburg A, Braun KP, van der Zwan A, Klijn $\mathrm{CJ}$ : Recent advances in moyamoya disease: Pathophysiology and treatment. Curr Neurol Neurosci Rep 14:423-013-0423-7, 2014 
JHN Journal, Vol. 9 [2014], Iss. 2, Art. 1

29. Zhao H, You C: Comparison of one-stage direct revascularization and medicine therapy for treatment of ischemic moyamoya disease.

Zhongguo Xiu Fu Chong Jian Wai Ke Za Zhi 23:1097-1100, 2009

30. Arias EJ, Derdeyn CP, Dacey RG,Jr, Zipfel GJ: Advances and surgical considerations in the treatment of moyamoya disease. Neurosurgery 74 Suppl 1:S116-25, 2014
31. Ahn IM, Park DH, Hann HJ, Kim KH, Kim HJ, Ahn HS: Incidence, prevalence, and survival of moyamoya disease in korea: A nationwide, population-based study. Stroke 45:10901095, 2014

32. Patel NN, Mangano FT, Klimo P,Jr: Indirect revascularization techniques for treating moyamoya disease. Neurosurg Clin N Am 21:553-563, 2010
33. Mukawa M, Nariai T, Matsushima Y, Ohno $\mathrm{K}$ : Clinical features of familial juvenile cases of moyamoya disease: Analysis of patients treated in a single institute over a 28-year period. J Neurosurg Pediatr 12:175-180, 2013

34. Mukawa M, Nariai T, Matsushima Y, Tanaka Y, Inaji $M$, Maehara $T$, et al: Long-term followup of surgically treated juvenile patients with moyamoya disease. J Neurosurg Pediatr 10:451-456, 2012 